\title{
PENGEMBANGAN MODEL PEMBELAJARAN ARCS (ATTENTION, RELEVANCE, CONFIDENCE, SATISFACTION) DENGAN WOLFRAM MATHEMATICA
}

\author{
Anisatul Farida ${ }^{1}$, Ratna Puspita Indah ${ }^{2}$. \\ ${ }^{1}$ Teknik Informatika, Universitas Duta Bangsa \\ 'email: anisatul farida@udb.ac.id \\ ${ }^{2}$ Sistem Informasi, Universitas Duta Bangsa \\ email: ietha_chu@yahoo.com
}

\begin{abstract}
This study aimed to develop a computer-based ARCS kind of classroom that valid, practical, and effective.This research adopting both qualitative and quantitative research and development with a method developed by Gall and the Borg. This research subject was students of engineering information Duta Bangsa Universityperiod 2018 / 2019.An instrument in this research consists of (1) an instrument assessment valid components model and devices supporting learning, (2) an instrument assessment practicality of faculty and students, and ( 3 ) instrument effectiveness of which includes sheets of the test results learning and chief appreciation students to learning linear algebra computerbased.The subject of this research is 25 students who took linear algebra. The study showed that Kind of classroom computer-based ARCS that met the criteria of valid, practical, and effective. Practicality ARCS kind of classroom computer-based based on (1) assessments from he got from his lecturers have reached very practical criteria; (2) assessing the from students we have achieved very practical criteria. The current effectiveness of ARCS kind of classroom computer-based based on (1) the results of THB students, fulfilled the criteria the current effectiveness of with the percentage $76 \%$, $(b)$ appreciation students learning ARCS against computer-driven which reached the criteria for good. It is also can be said that there is a correlation between appreciation students learning arcs against computer-based learning about mathematics with the results of the first significance $5 \%$ with a correlation coefficient $r=0,715$
\end{abstract}

Keywords: Kind of classroom ARCS, computer, linear algebra.

\section{PENDAhUluan}

Salah satu upaya untuk mencerdaskan dan mengembangkan potensi mahasiswa adalah melalui pendidikan yang di dalamnya dilakukan kegiatan bimbingan, pengajaran, atau latihan untuk kehidupan dimasayang akan datang. Melalui pendidikan, setiap individu dapat mengembangkan potensinya ke jenjang berikutnya yang lebih baik. Pendidikan merupakan investasi sumber daya manusia untuk jangka panjang dan berlangsung seumur hidup, oleh karena itu sistem pendidikan perlu dilakukan secara bertahap, berkesinambungan, dan menyeluruh untuk semua komponen dimulai dari tingkat yang paling dasar yaitu SD sampai pendidikan tinggi. Agar dapat mewujudkan tujuan pembelajaran tersebut, lembaga pendidikan diharuskan melakukan berbagai upaya guna memperbaiki dan meningkatkan 
Pengembangan Model Pembelajaran Arcs (Attention, Relevance, Confidence, Satisfaction) Dengan Wolfram Mathematica

Anisatul Farida, M.Pd ${ }^{1}$., Ratna Puspita Indah, S.Si., M.Pd ${ }^{2}$

mutu pendidikan di Indonesia. Dosen adalah pendidik profesional dan ilmuwan dengan tugas utama mentransformasikan, mengembangkan, dan menyebarluaskan ilmu pengetahuan, teknologi, dan seni melalui pendidikan, penelitian, dan pengabdian kepada masyarakat. Pembelajaran di kelas mewajibkan dosen merancang pembelajaran sekreatif mungkin sehingga ilmu bisa diterima dengan efektif oleh mahasiswa (Mulyatiningsih, 2014)

Cabang matematika yang diajarkan di sekolah salah satunya di perguruan tinggi adalah Aljabar. Khuzaeni (2012) berpendapat bahwa Aljabar adalah salah satu cabang matematika yang perlu dipelajari. Salah satu mata kuliah wajib di Fakultas Ilmu Komputer Universitas Duta Bangsa pada semester genap adalah Aljabar Linear. Mahasiswa masih mengalami kesulitan-kesulitan belajar dan belum memahami konsep dengan benar. Dari nilai-nilai pretest dan UTS terlihat rata-rata nilai mahasiswa adalah 69. Berdasarkan pengalaman dosen ketika mengajar, mahasiswa kesulitan ketika menerapkan teori dalam soal. Potensi mahasiswa yang besar serta pendukung misalnya fasilitas wifi di kampus ternyata belum cukup mumpuni untuk mendukung proses pembelajaran. Menurut Dimyati

dan Mudjiono (2010) pembelajaran adalah kegiatan guru secara terprogram dalam desain instruksional, untuk membuat siswa belajar secara aktif, yang menekanka pada penyediaan sumber belajar.

Berdasarkan hasil pengamatan selama pembelajaran di kelas terhadap Mahasiswa program studi Teknik Informatika semester genap pada tahun ajaran 2017/ 2018 yang mengambil mata kuliah Aljabar Linear, bahwa pembelajaran konvensional hanya dengan ceramah saja membuat Mahasiswa pasif dan suasana kelas menjadi sangat membosankan. Mahasiswa menjadi kurang aktif dalam mencari sumber belajar dan hanya menunggu instruksi dari dosen. Kalaupun tidak Mahasiswa hanya menggunakan sumber belajar dari dosen saja tanpa ada inisiatif mencari sumber belajar lain. Selain itu, berdasarkan hasil observasi ketika diskusi di dalam kelas tidak semua Mahasiswa terlibat secara aktif untuk berpendapat dan menemukan jawaban dari soal. Terlihat beberapa Mahasiswa yang hanya diam di kelas. Selain itu Mahasiswa juga belum mampu berpikir secara kritis untuk memecahkan dan menemukan jawaban.

Berdasarkan pengalaman ketika dosen mengajar Aljabar linear pada semester sebelumnya, mahasiswa kurang bisa menerima konsep dan mengaplikasikan konsep dalam soal. Oleh karena itu penulis memandang perlu adanya model pembelajaran yang lebih baik yang dapat meningkatkan pemahaman mahasiswa. Model pembelajaran yang dikembangkan dalam 
penelitian ini adalah model pembelajaran ARCS berbasis komputer dengan menggunakan aplikasi Wolfram Mathematica . Berdasarkan studi awal tentang model pembelajaran ARCS merupakan model pembelajaran yang mengutamakan perhatian Mahasiswa, menyesuaikan materi pembelajaran dengan pengalaman belajar Mahasiswa, menciptakan rasa percaya diri dalam diri Mahasiswa, dan menimbulkan rasa puas dalam diri Mahasiswa tersebut. Model ini perlu dikembangkan untuk mendukung proses pembelajaran. Model pembelajaran ARCS merupakan suatu bentuk pendekatan pemecahan masalah untuk merancang aspek motivasi serta lingkungan belajar dalam mendorong dan mempertahankan motivasi Mahasiswa untuk belajar (Siregar dan Nara, 2010).

Oleh karena itulah peneliti perlu mengembangkan model pembelajaran ARCS pada mata kuliah Aljabar Linear dengan Wolfram Mathematica. Konsep-konsep yang kompleks dan saling berhubungan memudahkan peneliti untuk mengaplikasikan soal dalam wolfram mathematica. Cara dosen mengemas gaya mengajar agar mudah ditangkap dan dimengerti oleh Mahasiswa adalah inti strategi Multiple Intelligences. Model pembelajaran ARCS mengutamakan perhatian Mahasiswa, menyesuaikan materi pembelajaran dengan pengalaman belajar Mahasiswa, menciptakan rasa percaya diri dalam diri Mahasiswa, dan menimbulkan rasa puas dalam diri Mahasiswa tersebut (Maidiyah dan Fonda, 2013).

Terdapat sembilan macam kecerdasan yang ada dalam diri manusia yang dikenal dengan Multiple Intelligences (Faridah, 2012). Kesembilan kecerdasan tersebu terdiri dari kecerdasan bahasa, kecerdasan logika matematika, kecerdasan musik, kecerdasan ruang, kecerdasan tubuh kinestika, kecerdasan alam, kecerdasan antar pribadi, kecerdasan intrapribadi, dan kecerdasan eksistensi. Chatib (2011: 108) menyatakan bahwa ketika ditarik ke dunia pendidikan maka Multiple Intelligences menjadi sebuah strategi pembelajaran. Strategi Multiple Intelligences dapat digunakan untuk materi apapun dalam semua bidang studi. Strategi ini dapat menampung semua metodologi pembelajaran (Putrawan, Rukayah, Hadiyah: 2012).

Dalam penelitian ini peneliti akan menggabungkan model pembelajaran ARCS Berbasis komputer. Teknologi informasi dan komunikasi yang sekarang ini berkembang pesat mengharuskan setiap pembelajaran menggunakan media yang menarik agar Mahasiswa termotivasi dalam pembelajaran yang merupakan salah satu karakteristik ARCS. Oleh karena itulah dalam penelitian ini peneliti akan menggabungkan model pembelajaran ARCS berbasis komputer yaitu dengan menggunakan aplikasi Wolfram Mathematica. Aplikasi ini 
Pengembangan Model Pembelajaran Arcs (Attention, Relevance, Confidence, Satisfaction) Dengan Wolfram Mathematica

Anisatul Farida, M.Pd ${ }^{1}$., Ratna Puspita Indah, S.Si., M.Pd ${ }^{2}$

memungkinkan mahasiswa mengerjakan soal aljabar yang bersifat kompleks dengan lebih efektif. Fasilitas wifi di kampus dan laboratorium juga memungkinkan mahasiswa memanfaatkan fasilitas untuk mendukung proses pembelajaran.

Berdasarkan uraian di atas, penulis mengambil judul penelitian "Pengembangan Model Pembelajaran ARCS (Attention, Relevance,Confidence, Satisfaction) dengan Wolfram Mathematica". Target luaran penelitian ini adalah model pembelajaran ARCS berbasis pada mata kuliah Aljabar Linear. Selain itu akan dihasilkan perangkat pembelajaran berupa silabus, RPP, dan Lembar Ajar Mahasiswa Wolfram Mathematica.

\section{METODE PENELITIAN}

Penelitian ini menggunakan metode Penelitian dan Pengembangan (Research and Development). Metode ini dirancang untuk mengembangkan suatu produk baru dan atau menyempurnakan produk yang telah ada dengan langkah-langkah yang dapat dipertanggungjawabkan (Sukmadinata, 2005; 163 - 145). Produk yang dikembangkan dalam penelitian adalah suatu model pembelajaran ARCS berbasis computer pada mata kuliah Aljabar Linear.tiga tahap utama, yaitu: pendahuluan, pengembangan, dan pengujian. Kualitas model pembelajaran dengan Wolfram Mtahematica mengacu pada kriteria kualitas menurut Nieveen yaitu meliputi valid, praktis, dan efektif. Pembelajaran berbasis komputer diterapkan pada Mahasiswa kelas 17-A4 Teknik Informatika Fakultas Ilmu Komputer Universitas Duta Bangsa yang melibatkan 25 Mahasiswa dan seorang dosen. Instrumen dalam penelitian ini adalah instrumen penilaian kevalidan komponen model dan perangkat pendukung pembelajaran, instrumen penilaian kepraktisan dari dosen dan Mahasiswa, dan yang terakhir yaitu instrumen keefektifan yang meliputi lembar tes hasil belajar dan angket apresiasi Mahasiswa terhadap pembelajaran Aljabar Linear dengan Wolfram Mathematica.

\section{HASIL DAN PEMBAHASAN}

\section{a. Pendahuluan}

Berdasarkan hasil penilaian ahli terhadap kevalidan model pembelajaran ARCS dengan Wolfram Mathematica, dapat ditunjukkan bahwa komponen-komponen pembelajaran ARCS mencapai kriteria sangat valid. Pada Tabel 2 dapat dilihat hasil penilaian ahli terhadap komponen model pembelajaran ARCS dengan Wolfram Mathematica. 
Tabel 2. Skor dan Kriteria Hasil Penilaian Kevalidan Model Pembelajaran ARCS dengan Wolfram Mathematica.

\begin{tabular}{|c|c|c|c|}
\hline No & Komponen & Rata-rata skor & Kriteria \\
\hline 1 & Sintak & 12.5 & Sangat valid \\
\hline 2 & Sistem sosial & 9 & Sangat valid \\
\hline 3 & Prinsip reaksi & 10 & Sangat valid \\
\hline 4 & $\begin{array}{c}\text { Dampak } \\
\text { pengiring\&Instruksional }\end{array}$ & 10 & Sangat valid \\
\hline
\end{tabular}

Untuk tabel 3, dapat dilihat secara ringkas hasil penilaian kevalidan perangkat pendukung pembelajaran.

Tabel 3. Skor dan Kriteria Hasil Penilaian Kevalidan Perangkat Pembelajaran dengan Wolfram Mathematica.

\begin{tabular}{|c|c|c|}
\hline Produk & Rata-rata skor & Kriteria \\
\hline SAP & 70,45 & Sangat valid \\
\hline LKS & 61 & Sangat valid \\
\hline THB & & Valid \\
\hline
\end{tabular}

Perangkat pendukung pembelajaran model pembelajaran ARCS berbasis komputer yang meliputi SAP, LKS, THB telah memenuhi kriteria valid. Dapat disimpulkan pula bahwa model pembelajaran ARCS dengan Wolfram Mathematica valid.

Sintaks model pembelajaran ARCS berbasisk omputer adalah (1) membangkitkan minat dan perhatian mahasiswa. Pada tahap ini peran dosen adalah apersepsi materi sebelumnya. Mahasiswa mengalami kesulitan untuk menggali informasi terdahulu. Oleh karena itulah peran dosen disini untuk mengingatkan kembali materi agar mempermudah dalam penerimaan konsep, (2) menjelaskan tujuan dan manfaat pembelajaran. Pada tahap ini pula difokuskan pada pembentukan kelompok belajar. Mahasiswa diberikan kebebasan memilih kelompok namun peran dosen adalah mengarahkan, (3) mengajukan pertanyaan berdasarkan soal cerita kehidupan sehari-hari (4) mereview materi sebelumnya. Peran dosen pada tahap ini adalah mengingatkan mahasiswa tentang materi sebelumnya dan yang mendukung materi pembelajaran (5) menyampaikan materi pembelajaran. Penyampaian materi pembelajaran disini dengan memanfaatkan komputer. Selain memanfaatkan teknologi, mahasiswa diharapkan dapat meningkatkan Multiplle Intelligences (6) memberi kesempatan kepada mahasiswa untuk berpartisipasi dalam pembelajaran. Tahap ini mahasiswa telah mampu mempresentasikan hasil kerja kelompok di depan kelas dengan 
Pengembangan Model Pembelajaran Arcs (Attention, Relevance, Confidence, Satisfaction) Dengan Wolfram Mathematica

Anisatul Farida, M.Pd ${ }^{1}$., Ratna Puspita Indah, S.Si., M.Pd ${ }^{2}$

membangun konsep sendiri. (7) memberi bimbingan belajar dan umpan balik. Umpan balik ini dapat berjalan dua arah. Artinya ketika dosen bertanya mahasiswa bias menjawab dan mahasiswa pula berani berpikir kritis (8) penguatan-penguatan positif untuk memberikan kepuasan mahasiswa terhadap pembelajaran. Tahap akhir ini ditarik kesimpulan dan menanyakan kembali kepada mahasiswa bagian konsep yang mana yang belum dipahami. Selain itu dosen harus memberikan feedback dan reward atas hasil dan presentasi mahasiswa

\section{b. Pengembangan}

Pengembangan terdiri dari tiga kegiatan yaitu pengembangan draf awal, uji coba model terbatas, dan uji coba lebih luas. Tingkat kevalidan model pembelajaran ARCS berbasis komputer beserta perangkat pendukungnya didapatkan dengan menggunakan lembar penilaian kevalidan yang diberikan kepada ahli. Penilaian kevalidan oleh ahli mencakup penilaian kevalidan komponen model pembelajaran ARCS dengan Wolfram Mathematica, RPP, LKS, dan THB. Sistem pendukung yang diperlukan untuk dapat melaksanakan model pembelajaran matematika ARCS berbasis komputer adalah Lembar Kegiatan Siswa (LKS) untuk menunjang pembelajaran matematika ARCS dengan Wolfram Mathematica. Dalam implementasi pembelajaran ARCS berbasis komputer, system pendukung berupa LKS yang menstimulasi kemampuan berpikir kritis.

Berdasarkan indikator penilaian aspek studi awal, diperoleh dara bahwa terdapat kesesuaian antara indikator pembelajaran dengan indikator media berbasis komputer. Kegiatan pembelajaran yang terjadi selama menggunakan model pembelajaran ARCS berbasis komputer sesuai dengan sintaks berupa kegiatan awal, kegiatan inti, dan kegiatan penutup. Data mahasiswa terkait penilaian mahasiswa dalam model pembelajaran ARCS berbasis komputer setelah dikonversi dari data kualitatif ke data kuantitatif adalah 4,05 yang berarti model pembelajaran ARCS berbasis komputer baik.

\section{c. Pengujian}

Tahap pengujian dalam penelitian akan dilakukan setelah semua tahap selesai. Dalam artikel ini yaitu baru selesai pada tahap pendahuluan dan pengembangan.

\section{KESIMPULAN}

Model pembelajaran ARCS yang telah dikembangkan pada penelitian ini mengacu pada model pembelajaran berbasis komputer pada mata kuliah Aljabar Linear. Luaran penelitian 
ini adalah SAP, silabus berbasis ARCS. Berdasarkan tahap-tahap pengembangan yang telah dilakukan, telah dihasilkan model pembelajaran ARCS dengan Wolfram Mathematica yang memenuhi kriteria valid, praktis, dan efektif. Kepraktisan model pembelajaran ARCS berbasis komputer berdasarkan penilaian dari dosen telah mencapai kriteria sangat praktis dan penilaian dari mahasiswa telah dicapai kriteria sangat praktis. Keefektifan model pembelajaran ARCS dengan Wolfram Mathematica berdasarkan hasil THB mahasiswa, telah memenuhi syarat keefektifan dengan persentase ketuntasan 76\%. Apresiasi mahasiswa terhadap pembelajaran ARCS dengan wolfram Mathematica mencapai kriteria baik. Selain itu dapat dikatakan bahwa terdapat hubungan yang positif antara apresiasi mahasiswa terhadap pembelajaran ARCS dengan Wolfram Mathematica terhadap hasil belajar matematika pada taraf signifikansi $\propto=0.05$ dengan koefisien korelasi $r=0,715$.

\section{REFERENSI}

Chatib, Munif. 2011. Dosennya Manusia: Menjadikan Semua Anak Istimewa dan Semua Anak Juara. Bandung: Kaifa.

Dimyati dan Mudjiono. 2010. Belajar dan Pembelajaran. Jakarta: Rineka Cipta.

Faridah, Nur. 2012. Pembelajaran Berbasis Multiple Intelligences Bagi Usia Pendidikan Dasar. UIN Sunan Kalijaga: Skripsi

Khuzaeni, A. 2012. Skripsi:" Perbedaan Prestasi Belajar Pokok Bahasan Pemfaktoran bentuk Aljabar Siswa yang diajar Menggunakan Pembelajaran Kooperatif Tipe Team Assisted Induvidualization (TAI) dengan Pembelajaran Ekspository kelas VIII SMPN 15 Malang”. Malang: UM

Maidiyah, Erni dan Fonda, Cut Zulisna. 2013. Penerapan Model Pembelajaran ARCS pada Materi Statistika di Kelas XI SMA Negeri 2 RSBI Banda Aceh. Jurnal Peluang, Volume 1, Nomor 2, April 2013, ISSN: 2302-5158

Mulyatiningsih, 2014. Pengembangan Model Pembelajaran. Bandung: UPI

Putrawan, Gde Darma, Rukayah, Hadiyah. 2012. Keefektifan Strategi Multiple Intelligences pada Pembelajaran IPS di Sekolah Dasar. UNS.

Siregar, Evaline. Hartini Nara. 2010. Teori Belajar dan Pembelajaran. Jakarta: Ghalia Indonesia 